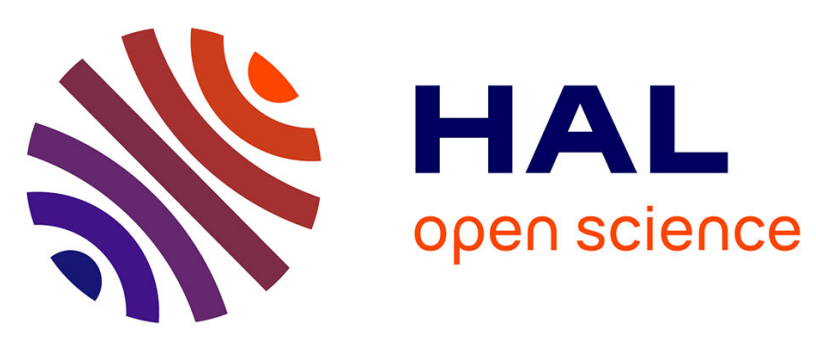

\title{
Geometric morphometrics of the shoulder girdle in extant turtles (Chelonii)
}

Marion Depecker, Christine Berge, Sabine Renous, Xavier Penin

\section{To cite this version:}

Marion Depecker, Christine Berge, Sabine Renous, Xavier Penin. Geometric morphometrics of the shoulder girdle in extant turtles (Chelonii). 2006. hal-00109990

\section{HAL Id: hal-00109990 https://hal.science/hal-00109990}

Preprint submitted on 6 Nov 2006

HAL is a multi-disciplinary open access archive for the deposit and dissemination of scientific research documents, whether they are published or not. The documents may come from teaching and research institutions in France or abroad, or from public or private research centers.
L'archive ouverte pluridisciplinaire HAL, est destinée au dépôt et à la diffusion de documents scientifiques de niveau recherche, publiés ou non, émanant des établissements d'enseignement et de recherche français ou étrangers, des laboratoires publics ou privés. 


\title{
Geometric morphometrics of the shoulder girdle in extant turtles (Chelonii)
}

\author{
Marion Depecker, ${ }^{1}$ Christine Berge, ${ }^{1}$ Xavier Penin ${ }^{2}$ and Sabine Renous ${ }^{1}$ \\ ${ }^{1}$ Muséum National d'Histoire Naturelle, Paris, France \\ ${ }^{2}$ Département d'Orthodontie, Faculté de Chirurgie Dentaire, Montrouge, France
}

\begin{abstract}
The aim of this study was to identify shape patterns of the shoulder girdle in relation to different functional and environmental behaviours in turtles. The Procrustes method was used to compare the shoulder girdles (scapula and coracoid) of 88 adult extant turtles. The results indicate that four shape patterns can be distinguished. The shoulder girdles of (1) terrestrial (Testudinidae), (2) highly aquatic freshwater (Trionychidae, Carettochelyidae) and (3) marine turtles (Cheloniidae, Dermochelyidae) correspond to three specialized morphological patterns, whereas the shoulder girdle of (4) semi-aquatic freshwater turtles (Bataguridae, Chelidae, Chelydridae, Emydidae, Kinosternidae, Pelomedusidae, Platysternidae, Podocnemididae) is more generalized. In terrestrial turtles, the long scapular prong and the short coracoid are associated with a domed shell and a mode of locomotion in which walking is predominant. By contrast, highly aquatic freshwater turtles share traits with marine turtles. In both, the short scapular prong and the long coracoid are associated with a flat shell, and swimming locomotion. The enlarged attachment sites of the biceps, coracobrachialis magnus, and supracoracoideus also give these strong swimmers a mechanical advantage during adduction and retraction of the arm. Increasing size leads to allometrical shape changes that emphasize mechanical efficiency both in terrestrial and in aquatic turtles.
\end{abstract}

Key words Chelonians; coracoid; locomotion; Procrustes analysis; scapula; shape pattern.

\section{Introduction}

Over the last decade, anatomical studies have been complemented by geometric morphometrics, allowing the calculation and visualization of global shape changes in organs or organisms. Procrustes superimposition is the most effective method (Gower, 1975; Bookstein et al. 1985; Rohlf \& Slice, 1990; Goodhall, 1991, 1995) for creating spatial graphical representations of shape variations in complex anatomical structures using threedimensional (3D) data (O'Higgins et al. 1990; Penin, 1997; Penin \& Baylac, 1999; Penin \& Berge, 2001; Ponce de León \& Zollikofer, 2001; Hennessy \& Stringer, 2002). The shoulder girdle of turtles, formed by the scapula and

\section{Correspondence}

Dr Sabine Renous, Muséum National d'Histoire Naturelle,

Département d'Ecologie et de Gestion de la Biodiversité, USM 302 (FRE 2696 (NRS), Adaptations et Evolution des Systèmes Ostéomusculaires, Case Postale 55, 57 rue Cuvier, 75231 Paris cedex 05, France.

T: 01407933 09; F: 01407937 73, E: renous@mnhn.fr

Accepted for publication 23 October 2005 the coracoid, reaches maximal complexity with a large range of size and shape variations in the lower tetrapods, especially in turtles with an extremely developed acromial process. The girdle constitutes a structure for which the Procrustes method provides a powerful tool for functional morphology and taxonomy. In previous studies, the Procrustes method was used to distinguish between size-related shape changes (allometry) and shape changes corresponding to taxonomic differences (Penin et al. 2002; Berge \& Penin, 2004). In the present study, the same approach is applied to distinguish morphological groups, in terms of allometry, and functional adaptations. The material includes a wide range of specimens representing numerous species of many sizes (due to continuous growth at the adult stage). Therefore, we have not studied systematics but rather functional shape changes.

\section{Background to ecological and locomotor comparison}

Extant turtles live in a wide range of terrestrial and fresh- and sea-water environments (ponds, lakes, streams, 
large rivers, torrents, estuaries, ocean, etc.). For this reason, Romer (1956) distinguished land tortoises, marine and freshwater turtles, whereas Walker (1973) used the terms 'terrestrial', 'semi-aquatic' and 'aquatic'. Pritchard (1979) introduced the term 'semi-terrestrial' to describe some freshwater turtles. Ecological differences may correspond to functional differences in the patterns of locomotion. Walker (1971a) was among the first to study the involvement of the shoulder girdle in the movement of the forelimb during walking in a freshwater turtle (Chrysemys picta). Other studies concern analyses of gait during walking in various freshwater and terrestrial turtles (Hildebrand, 1966; Zug, 1972; Walker, 1979; Jayes \& Alexander, 1980; Williams, 1981). Van Leeuwen et al. (1981) specified mechanical stresses in tortoise leg muscles during walking. The movements of marine turtles were analysed (Walker, 1971b; Renous, 1988, 1993, 1995; Renous \& Bels, 1989; Renous et al. 1999), and compared with the swimming movements of freshwater turtles. Davenport et al. (1984) and Pace et al. (2001) compared the kinematics of forelimbs in two species of freshwater turtles, one species (Trachemys scripta) being more generalized and the other (Apalone spinifera) morphologically highly specialized for swimming. They demonstrated that there are two different functional patterns, corresponding, respectively, to species which travel frequently over land and those which spend little time out of water. Several studies pointed out variations in the structure of the locomotor apparatus (Boulenger, 1889; Hoffmann, 1890) in relation to environment (Romer, 1956; Walker, 1973). More specifically, Walker (1962, 1971a, 1972) attempted to establish relationships between limb structure, body form and walking patterns in one species (C. picta). Zug (1971) made an extended comparative study of pelvic and hindlimb morphology and locomotion in cryptodiran turtles.

\section{Aim of the study}

The shoulder girdle seems to be particularly appropriate for comparative study because of the predominant role of the forelimb in propulsion, both in terrestrial and in aquatic environments. This is particularly true for marine turtles, in which propulsion is mainly driven by the forepaddles (Davenport et al. 1984; Renous, 1988, 1993; Renous \& Bels, 1989; Renous et al. 1999). In the present study, we use geometric morphometrics to specify morphological traits in the shoulder girdle that can be used to characterize morphofunctional groups of turtles. Our aim is to discuss shape differences in relation to body shape and the use of the forelimbs for different locomotor behaviours related to specific habitats. The method does not predict any phylogenetic affinities because Pleurodira and Cryptodira are not considered separately in this study. Size scaling in turtles is particularly important. Body weight in adult terrestrial turtles ranges from $140 \mathrm{~g}$ (Homopus signatus) to $300 \mathrm{~kg}$ (Dipsochelys gigantea), and in adult marine turtles from $45 \mathrm{~kg}$ (Lepidochelys kempii) to $900 \mathrm{~kg}$ (Dermochelys coriacea). To summarize, the purpose of the study is to understand how size interacts with locomotor adaptations in aquatic and terrestrial environments.

\section{Material and methods}

\section{Sample}

The shoulder girdles of 88 extant adult specimens, corresponding to 13 families and 57 species, were measured (Table 1). The specimens belong to the collections at the Muséum National d'Histoire Naturelle (Paris), except for one specimen (Carettochelys insculpta) belonging to the Naturhistorisches Museum (Vienna).

\section{Anatomy of the shoulder girdle}

The shoulder girdle of extant turtles is a triradiate structure with a dorsal scapular prong, a ventral anterior acromial process and a ventral posterior coracoid (Fig. 1). The acromial process is an extension of the scapula (Friant, 1942; Walker, 1973; Lee, 1996) rather than a separate element, homologous to the anterior part of the coracoid, as in other reptiles (Gaffney, 1990). The scapular prong constitutes a vertical column, dorsally and medially articulated with the shell. Ventrally, the acromial process also has a column-like shape. The two ends of the scapula are capped by cartilages and are connected by ligaments to the entoplastron. The triangular coracoid is essentially horizontally orientated. The coracoid is capped by an epicoracoid cartilage, but is not connected by ligaments to the entoplastron (Walker, 1973). The glenoid cavity is formed by both the coracoid and the scapula.

\section{Landmarks}

Sixteen landmarks have been defined according to the three levels of homology given in Bookstein (1991) 
Table 1 The specimens studied

\begin{tabular}{|c|c|c|c|c|c|}
\hline Family/Species & $n$ & No. & Family/Species & $n$ & No. \\
\hline Testudinoidea & & & Chelydridae & & \\
\hline Testudinidae & & & Chelydra serpentina & 1 & 53 \\
\hline Astrochelys radiata & 3 & $1,2,3$ & Platysternidae & & \\
\hline Centrochelys sulcata & 3 & $4,5,6$ & Platysternon megacephalum & 1 & 54 \\
\hline Chelonoidis carbonaria & 4 & $7,8,9,10$ & Kinosternidae & & \\
\hline Chelonoidis denticulata & 3 & $11,12,13$ & Kinosternon leucostomum & 1 & 55 \\
\hline Chersina angulata & 1 & 14 & Kinosternon subrubrum & 1 & 56 \\
\hline Dipsochelys gigantea & 3 & $15,16,17$ & Chelidae & & \\
\hline Geochelone elegans & 1 & 18 & Chelus fimbriatus & 1 & 57 \\
\hline Homopus areolatus & 2 & 19,20 & Hydromedusa tectifera & 1 & 58 \\
\hline Indotestudo elongata & 2 & 21,22 & Platemys platycephala & 1 & 59 \\
\hline Kinixys belliana & 1 & 23 & Pelomedusidae & & \\
\hline Kinixys erosa & 1 & 24 & Pelomedusa subrufa & 1 & 60 \\
\hline Manouria emys & 2 & 25,26 & Pelusios subniger & 1 & 61 \\
\hline Manouria impressa & 1 & 27 & Podocnemididae & & \\
\hline Stigmochelys pardalis & 1 & 28 & Erymnochelys madagascariensis & 1 & 62 \\
\hline Testudo graeca & 4 & $29,30,31,32$ & Peltocephalus dumerilianus & 1 & 63 \\
\hline Testudo hermanni & 1 & 33 & Podocnemis expansa & 1 & 64 \\
\hline Testudo kleimanni & 1 & 34 & Trionychoidea & & \\
\hline Testudo marginata & 2 & 35,36 & Trionychidae & & \\
\hline Emydidae & & & Amyda cartilaginea & 2 & 65,66 \\
\hline Clemmys guttata & 1 & 37 & Apalone ferox & 1 & 67 \\
\hline Clemmys insculpta & 1 & 38 & Aspideretes gangeticus & 1 & 68 \\
\hline Emys orbicularis & 1 & 39 & Aspideretes hurum & 1 & 69 \\
\hline Malaclemys terrapin & 1 & 40 & Cycloderma aubryi & 3 & $70,71,72$ \\
\hline Pseudemys rubriventris & 1 & 41 & Lissemys punctata & 1 & 73 \\
\hline Terrapene carolina & 2 & 42,43 & Pelodiscus sinensis & 1 & 74 \\
\hline Trachemys scripta & 1 & 44 & Trionyx triunguis & 2 & 75,76 \\
\hline Bataguridae & & & Carettochelyidae & & \\
\hline Chinemys reevesii & 1 & 45 & Carettochelys insculpta & 1 & 77 \\
\hline Geoclemys hamiltonii & 1 & 46 & Chelonioidea & & \\
\hline Geoemyda spengleri & 1 & 47 & Cheloniidae & & \\
\hline Hieremys annandalii & 2 & 48,49 & Caretta caretta & 3 & $78,79,80$ \\
\hline Malayemys subtrijuga & 1 & 50 & Chelonia mydas & 4 & $81,82,83,84$ \\
\hline Melanochelys trijuga & 1 & 51 & Eretmochelys imbricata & 3 & $85,86,87$ \\
\hline \multirow[t]{2}{*}{ Rhinoclemmys punctularia } & 1 & 52 & Dermochelyidae & & \\
\hline & & & Dermochelys coriacea & 1 & 88 \\
\hline
\end{tabular}

Classification according to King \& Burke (1997), except within Testudinidae (Bour \& Dubois, 1984), and the Podocnemididae family (de Broin, 1988; Meylan, 1996). $n$ : number of specimens studied; No.: specimens represented in Fig. 3.

(Table 2, Fig. 2). Six landmarks are type I: these correspond to contact points between structures. Two landmarks are type II corresponding to process extremities. Eight landmarks are type III and are the result of constructions. The 3D coordinates of the 16 landmarks were digitized using a Microscribe (3D Revpro DX, precision of $0.1 \mathrm{~mm}$ ).

\section{Procrustes superimposition and statistical analysis}

Procrustes superimposition uses landmark coordinates. The set of landmarks from each specimen builds a simplified shape termed a 'figure'. Procrustes super- imposition scales, translates and rotates all the figures to minimize distances between homologous landmarks (generalized least-squares criterion) (Gower, 1975; Rohlf \& Slice, 1990). The size of each specimen is an overall size calculated using all the landmarks (i.e. the square root of the sum of the squared deviations of landmarks from the centre of the figure). The shape is defined by Procrustes residuals, which are the deviations of landmarks from the mean shape. Therefore, 48 variables (16 landmarks in three spatial dimensions) describe a given specimen. Such a large number of variables generates statistical problems (Rao, 1966). Statistical tests require a low number of variables as comparison with 
Table 2 Landmarks

\begin{tabular}{lll}
\hline No. & Definition \\
\hline 1 & Medial anterior angle of the coracoid & Type \\
2 & Medial posterior angle of the coracoid & Posterior border of the coracoid (maximum curvature) \\
3 & Posterior border of the coracoid (coracoid collar) & I \\
4 & Pentral extremity of the glenoid cavity \\
5 & Posterior border of the glenoid cavity (1/2 of the height) \\
6 & Anterior border of the glenoid cavity (1/2 of the height) \\
7 & Base of the scapular prong (maximum curvature) \\
8 & Lateral dorsal angle of the scapular prong \\
9 & Medial dorsal angle of the scapular prong \\
10 & Limit between the scapula and the acromial process (maximum curvature) \\
11 & Medial anterior angle of the acromial process \\
12 & Medial posterior angle of the acromial process & III \\
13 & Limit between the coracoid and the acromial process (maximum curvature) \\
15 & Anterior border of the coracoid (coracoid collar) & III \\
16 & III \\
\hline
\end{tabular}

No.: number of landmarks in Fig. 2. Types I, II, and III: homology in Bookstein (1991).

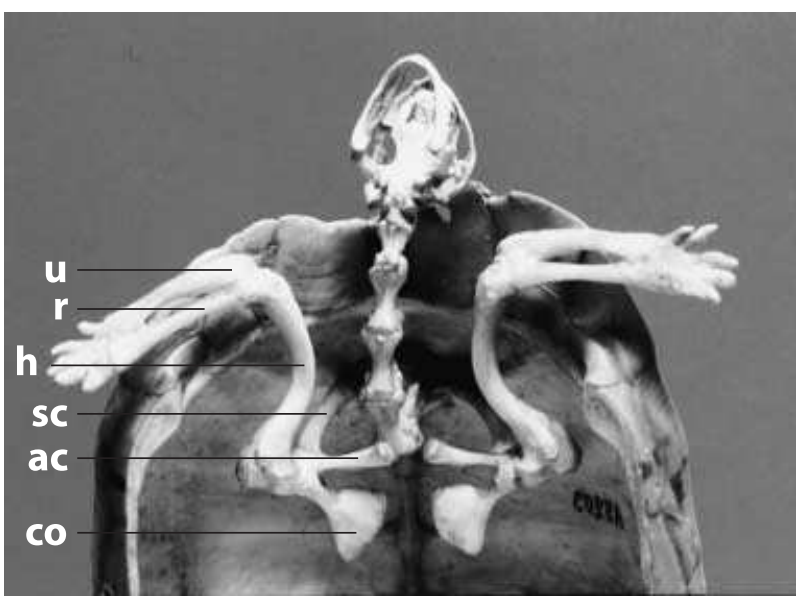

Fig. 1 Skeleton of the shoulder and forearm in connection with the shell and vertebral column in a terrestrial turtle (Kinixys belliana, ventral view, plastron removed). ac, acromial process; co, coracoid; $h$, humerus; r, radius; sc, scapular prong; u, ulna.

the number of specimens. Principal Component Analysis (PCA) allows us to reduce the number of variables. Statistical tests are computed with a small number of principal components (PCs).

Allometry calculations use multivariate regression in which the explicative variable is the centroid size and the dependent variables are the shape variables (Procrustes residuals or PC scores) (Klingenberg, 1996). The multivariate regression developed by Mardia et al. (1979) and Krzanowski (1988) has already been used in similar studies (Hennessy \& Stringer, 2002; Penin et al.

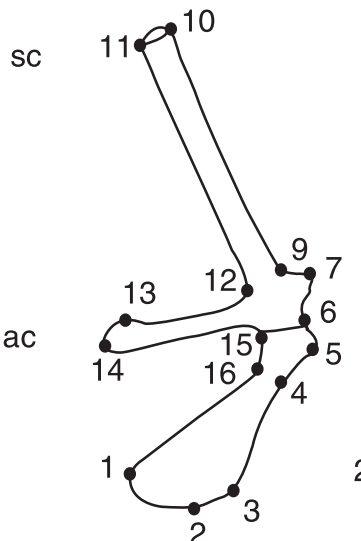

$\mathrm{CO}$

A

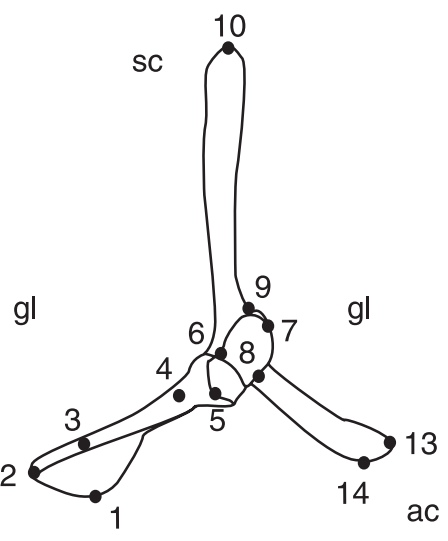

$\mathrm{CO}$

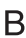

Fig. 2 The 16 landmarks recorded on the right shoulder girdle in a semi-aquatic freshwater turtle (Chelydra serpentina).

(A) Dorsal posterior view; (B) lateral view. ac, acromial process; co, coracoid; gl, glenoid cavity; sc, scapular prong. For definition of landmarks, see Table 2.

2002; Berge \& Penin, 2004). With this method, allometry is defined in the sense of Gould (1966), Mosiman \& James (1979) and Bookstein (1991) as shape changes related to size increase. Five separate analyses were performed to calculate allometric shape vectors in groups (all turtles, terrestrial, semi-aquatic, highly aquatic freshwater turtles and marine turtles). Shape differences between groups were identified by a Fisher discriminant function. In the same way as allometry, the discriminant vector is the linear combination of the shape variables 
(Procrustes residuals or PC scores) that best differentiates the groups taken in pairs (semi-aquatic vs. terrestrial, semi-aquatic vs. highly aquatic freshwater turtle).

For both multivariate regression and discrimination, the statistical analysis comprises two steps. First, a test of significance ( $F$-test giving $F=F$-value, d.f. = numbers of degrees of freedom, $P=$ probability for the null hypothesis) uses a low number of PCs to increase significance (Berge \& Penin, 2004). In a second stage, shape vectors (to visualize shape changes related to regression or discrimination) can be calculated either with the significant PC or all the PCs. The graphical results are identical (Penin, 1999; Berge \& Penin, 2004).

Superimposition, PCA, allometric shape vectors and discriminant vectors, graphs and $F$-tests were computed using APS Software version 2.21 (Penin, 2000-2003).

\section{Results}

\section{The four different patterns}

PCA of the 88 specimens shows that the two first PCs (representing $73.2 \%$ of the total shape variance) separate all the specimens into four main groups (Fig. 3). Group I comprises the family of terrestrial turtles (Testudinidae). Group II contains eight families of freshwater turtles (Bataguridae, Chelidae, Chelydridae,
Emydidae, Kinosternidae, Pelomedusidae, Platysternidae and Podocnemididae); Group III contains two families of freshwater turtles (Carettochelyidae and Trionychidae) and Group IV contains the two families of marine turtles (Cheloniidae, Dermochelyidae). Note that the majority of freshwater turtles (group II) are close to the terrestrial turtles, whereas Carettochelyids and Trionychids (group III) are close to the marine turtles. Since shape differences between groups correspond to composite variations along $\mathrm{PC} 1$ and $\mathrm{PC} 2$, we preferred to describe shape patterns in terms of discriminant traits calculated as combinations of PCs (see below).

\section{Size-related shape changes}

Figure 4(A) shows allometry in all turtles. The shape of the shoulder girdle gradually modifies with size in all turtles. Figure 4(B-D) show within-group allometries. Regression tests are significant in all turtles $(F=31.9$; d.f. $\left.=5,82 ; P<10^{-6}\right)$, in terrestrial turtles $(F=14.1$; d.f. $\left.=5,30 ; P<10^{-6}\right)$, in highly aquatic freshwater turtles $(F=12.0 ;$ d.f. $=4,8 ; P<0.002)$ and in marine turtles $(F=5.4 ;$ d.f. $=5,5 ; P<0.04)$. Only in semi-aquatic freshwater turtles was the regression test non-significant.

Figure 5(A-D) depict allometric shape changes. The main changes concern the lengths of the three parts of the shoulder girdle. Shape changes seem very similar
Fig. 3 The 88 specimens projected onto the plane of the first principal component PC1 (52.7\% of variance) and PC2 (20.9\% of variance). Pleurodira and Cryptodira are not distinguished in the analysis. Group I (filled circles): Testudinidae (specimens 1-36). Group II (open squares): Emydidae (37-44), Bataguridae (45-52), Chelydridae (53), Platysternidae (54), Kinosternidae (55, 56), Chelidae (57-59), Pelomedusidae $(60,61)$, Podocnemididae (62-64). Group III (solid squares): Trionychidae (65-76), Carettochelyidae (77). Group IV (open triangles): Cheloniidae (78-87) and Dermochelyidae (88). For species names, see Table 1. Solid lines: shape changes along PC1 and PC2; dotted lines: consensus (mean shape).

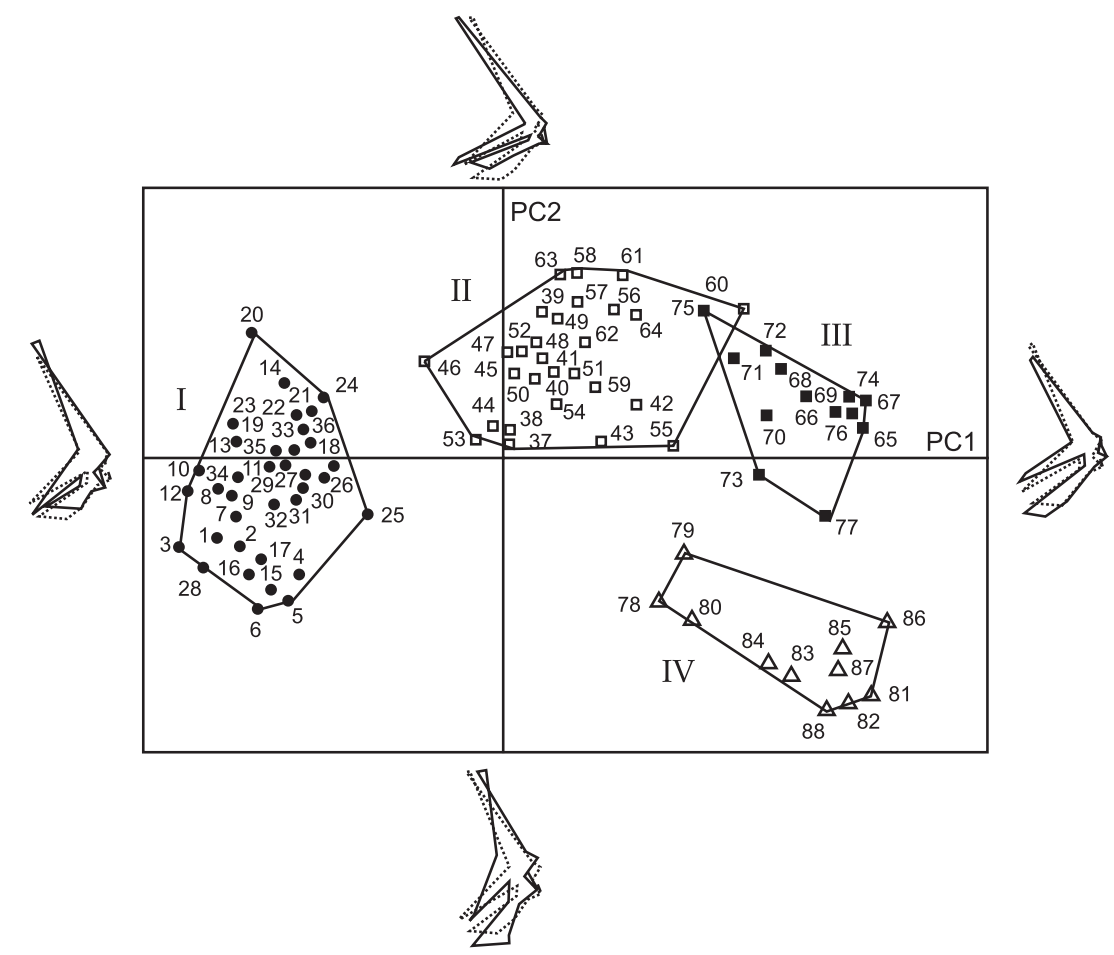



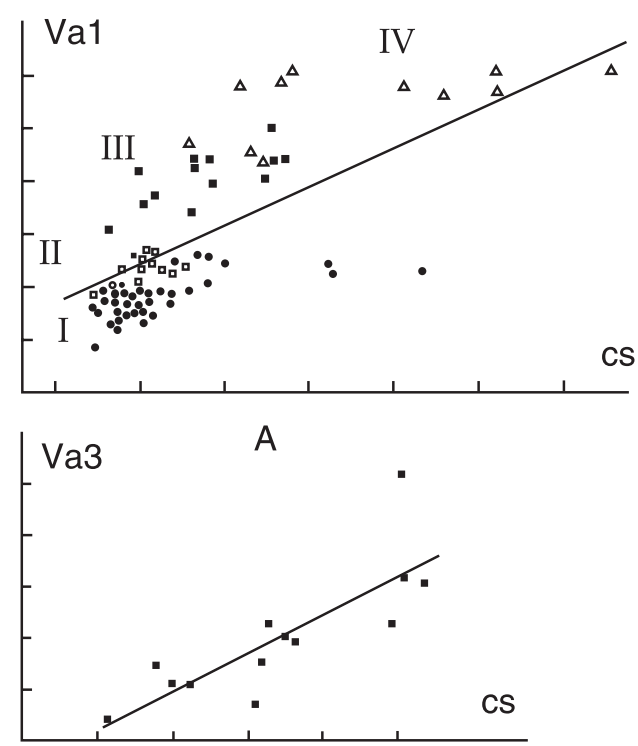

C

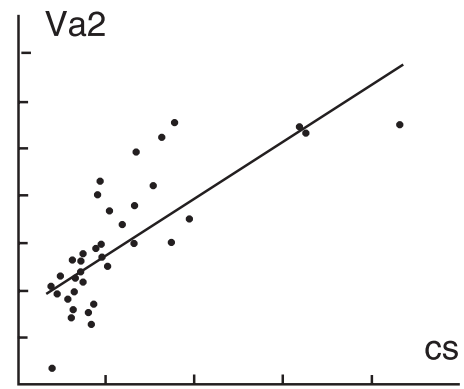

B

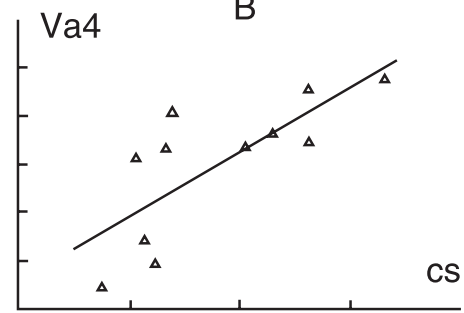

D
Fig. 4 Allometric shape vectors calculated in various groups of turtles. (A) All turtles; (B) terrestrial turtles;

(C) highly aquatic freshwater turtles; (D) marine turtles. Cs, centroid size; Va1, allometric shape vector calculated in all turtles; Va2, in terrestrial; Va3, in highly aquatic freshwater; Va4, in marine turtles. Groups I-IV and symbols defined as in Fig. 3. for all turtles (Fig. 5A), for terrestrial (Fig. 5B), for highly aquatic freshwater (Fig. 5C) and for marine turtles (Fig. 5D). The coracoid becomes proportionally longer with size (broader in terrestrial turtles), whereas the scapula and the acromial process become proportionally shorter. Allometric shape changes also correspond to a wider angle between the scapular prong and the acromial process and, consequently, a more developed glenoid cavity region.

\section{The discriminant traits in terrestrial, freshwater and marine turtles}

Four analyses were performed to calculate the shape that discriminates each group of turtles from the group of semi-aquatic freshwater turtles used as a reference. The discrimination tests are highly significant: terrestrial turtles, $F=154$, d.f. $=3,56, P<10^{-6}$; highly aquatic freshwater turtles, $F=45.6$, d.f. $=3,30, P<10^{-6}$; marine turtles, $F=99.7$, d.f. $=3,35, P<10^{-6}$.

\section{Terrestrial turtles}

When compared with the semi-aquatic freshwater turtles, these have a more massive shoulder girdle (Fig. 6A). The glenoid cavity is clearly larger while the angle formed by the scapula and the acromial process (landmarks 11, 12, 13) is much wider in terrestrial turtles than in semi-aquatic turtles. The scapula of the terrestrial turtles is longer and more vertically orientated.

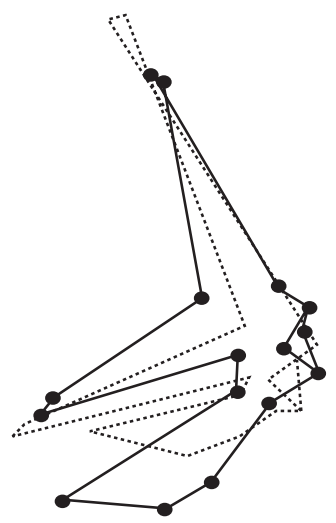

A

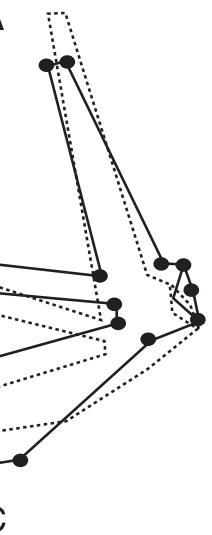

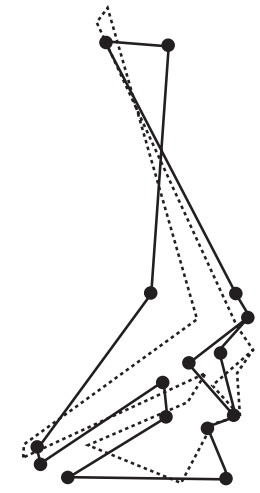

B

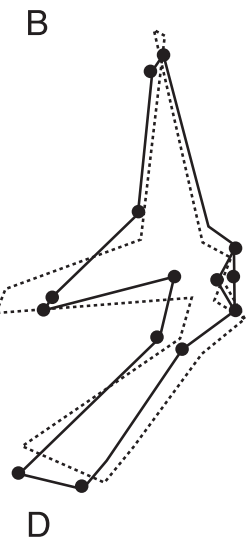

Fig. 5 Allometric shape changes associated with allometric shape vectors (dorsal posterior view). (A) All turtles;

(B) terrestrial turtles; (C) highly aquatic freshwater turtles;

(D) marine turtles. Dotted lines: the smallest specimens; solid lines: the largest specimens. 


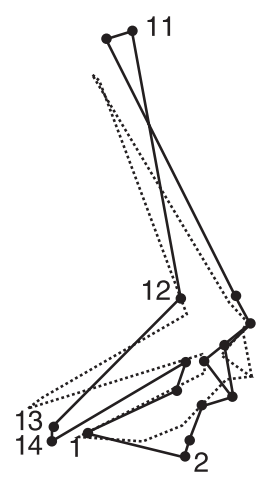

A

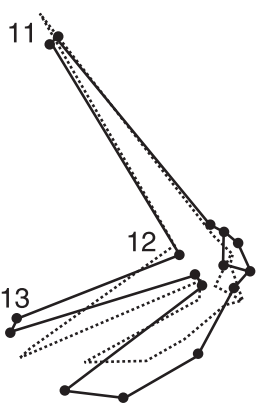

B

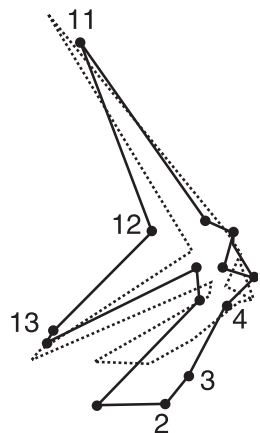

C
Fig. 6 Discriminant traits in turtles (dorsal posterior view). The semi-aquatic freshwater turtles (dotted lines) are used as a reference to compare with other groups (solid lines).

(A) terrestrial turtles; (B) highly aquatic freshwater turtles; (C) marine turtles.

The coracoid is shorter and broader, and the extremities of the coracoid and the acromial process are displaced towards a more ventral position (lower position of landmarks 1, 2 and 13, 14).

Highly aquatic freshwater turtles

The nine species of highly aquatic freshwater turtles studied, belonging to two families (Carettochelyids and Trionychids), are clearly separated from the other species (Fig. 3). They are described as highly specialized for swimming, in comparison with the other species which are morphologically and functionally more generalized. We calculated the discriminant vector between these two groups. Figure 6 (B) compares the specialized shape to the generalized one. The highly aquatic freshwater turtles have a more developed shoulder girdle in its ventral part (coracoid and acromial process) relative to the dorsal scapula. We may observe that in highly specialized freshwater species, the coracoid is longer, broader and more curved. The scapula is shorter and makes an acute angle with the acromial process (landmarks 11-13).

\section{Marine turtles}

When compared with the semi-aquatic freshwater turtles, these have a more massive shoulder girdle (Fig. 6C). The coracoid is longer while the acromial process and the scapula are shorter. The coracoid has a straight posterior border (landmarks 2-4) in comparison with the freshwater turtles, which have a curved border. Moreover, in marine turtles, the scapula makes an obtuse angle with the acromial process (landmarks 11-13).

\section{Discussion}

As observed by Joyce \& Gauthier (2004), 'a deeper understanding of living turtles is ... the key to revealing the ecology of their fossil relatives'. Their strong acrossclade correlation between hand morphology and habitat preferences observed among extant turtles provides palaeoecological evidence to suggest that turtles first evolved in a terrestrial habitat and only later moved into aquatic environments. Our study, using a different morphological approach, supplies complementary data to support such a hypothesis. Our work reveals four distinct morphological patterns of the shoulder girdle independent of size. The two most different patterns are those of the terrestrial and marine turtles. Two other freshwater turtle patterns occupy an intermediate position in terms of size and shape. The shoulder pattern of the semi-aquatic species is close to that of terrestrial turtles, whereas the shoulder pattern of the highly aquatic freshwater species is close to that of marine turtles.

\section{Generalist and specialist turtles}

It is generally acknowledged that modern terrestrial and marine turtles may have evolved independently from morphologically and functionally less-specialized freshwater turtles (Gaffney, 1975, 1984; Gaffney \& Meylan, 1988; Gaffney et al. 1991; Shaffer et al. 1997). Our study provides precise arguments to reinforce this hypothesis. The shoulders of terrestrial and marine turtles appear to be highly specialized. Body size, which may increase considerably in tortoises and marine turtles, accentuates morphological specializations. Within the group of freshwater turtles, we may distinguish two different patterns. Semi-aquatic freshwater turtles appear to have an intermediary shape pattern between terrestrial and marine turtles, and therefore may be regarded as generalized. Large species belonging to the Trionychids and Carettochelyids have a more specialized pattern, which resembles that of marine turtles. Pace et al. (2001) compared two species belonging to the two groups (semi-aquatic and highly aquatic freshwater turtles). In terms of habitat, morphology and limb function, one is generalized (red-eared slider), 
and the other (spiny softshell turtle) specialized. The generalized species spends time in both terrestrial and aquatic habitats, whereas the specialized species spends little time out of water. The former possesses twice as much forelimb surface area as the generalized species for generating drag-based thrust in swimming (Pace et al. 2001). These strong swimmers have extensive webbing between the toes of both forefeet and hindfeet (Trionychids), and a real forepaddle (Carettochelyids), as in marine turtles (Cann, 1998). Highly aquatic turtles generate specific efficient movements for swimming as compared with semi-aquatic ones (Pace et al. 2001).

\section{Allometric shape changes in the shoulder girdle}

We observed a progressive shape change of the shoulder girdle morphology with increased size in terrestrial, highly aquatic freshwater turtles and marine turtles (only semi-aquatic turtles display insignificant allometric shape changes). Within these groups, the shoulder girdle tends to become more massive and robust, with broader muscular surfaces in the scapula and coracoid in large turtles. In aquatic turtles, these shape changes give rise to very powerful antagonist dorsal abductor and ventral adductor muscles. The subscapularis muscle, inserted on the lateral surface of the scapula, acts as an important abductor of the forelimb, and the supracoracoideus and coracobrachialis magnus muscles, inserted on the ventral and dorsal surface of the coracoid, act as adductors of the forelimb (Walker, 1973).

With continuous growth, some turtles may attain extremely large body size. The smallest species are found among the terrestrial and the generalized freshwater turtles, whereas the largest species are found in terrestrial and marine turtles. The largest highly aquatic turtles are the same size as the smallest marine turtles. Some variants in allometric shape changes are probably due to locomotor adaptations. For example, when size increases, the coracoid becomes broader in terrestrial turtles, whereas it becomes longer in marine turtles, and both longer and broader in highly aquatic freshwater turtles.

\section{Morphological patterns related to locomotor behaviours}

The results strongly support the existence of four different shoulder patterns in turtles. These morphological patterns have been calculated independently of size.
They may correspond to functional patterns, related to the locomotor constraints imposed by the different habitats in which turtles live. The small freshwater turtles comprise eight families belonging to pleurodires and cryptodires. This large group occupies both terrestrial and aquatic environments. Their shoulder girdle appears to have a generalized shape, intermediate between that of terrestrial turtles and that of aquatic turtles. Here, the term 'semi-aquatic' describes turtles which possess such a morphological pattern. The terrestrial Testudinids constitute a homogeneous group in terms of shoulder shape. Large species keep the same morphological pattern, differing only slightly according to allometric shape changes. In general, they are well adapted to a strictly terrestrial environment. The term 'terrestrial turtles' chosen here is synonymous with 'land tortoises', traditionally used to distinguish them from all other families. The marine turtles are Cheloniids and Dermochelyids, two morphologically close families often regarded as extant sister-groups (Gaffney, 1975, 1984; Gaffney \& Meylan, 1988; Gaffney et al. 1991; Hirayama, 1995; Shaffer et al. 1997). They are highly specialized for swimming, both on account of their limb morphology (forepaddles) and their use of synchronous and simultaneous movements of the forelimbs, or of the hindlimbs, or of both simultaneously (Davenport et al. 1984; Davenport \& Clough, 1986; Davenport, 1987), whereas the others, like most tetrapods, use alternating limbs (Grillner, 1975, 1981). The shoulder girdle morphology confirms a certain homogeneity in the group of Cheloniids and Dermochelyids, except Caretta caretta, which appears to be closer to less specialized turtles (freshwater turtles) in our analysis. Among the freshwater turtles, two families, the Trionychids and the Carettochelyids, are regarded as morphologically close and sister-groups (Bickham et al. 1983; Gaffney \& Meylan, 1988; Meylan \& Gaffney, 1989; Gaffney et al. 1991; Shaffer et al. 1997). They share specialized traits with the marine turtles corresponding to their highly aquatic lifestyle. However, the Trionychids and the Carettochelyids preserve anatomical traits in common with the generalized freshwater turtles. Our results suggest that such specialized traits, which characterize strong aquatic adaptation, appeared several times in the evolution of turtles. These convergent traits concern both the shoulder girdle and limb extremities. Among the freshwater turtles, the locomotor behaviour of Carettochelys insculpta is closest to that of the marine turtles (Georges, 1988). When swimming, its 
Fig. 7 Shape and orientation of the shoulder girdle elements in relation to the shape of the shell (anterior view). (A) Terrestrial turtles; (B) highly aquatic freshwater turtles; $(C)$ marine turtles. The shape of the shoulder girdle results from the calculation of discriminant traits (see Fig. 6). The extremities of the scapular prong and the acromial process are placed on a vertical line.

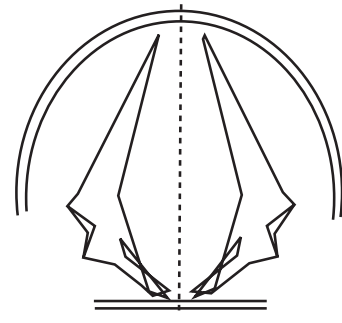

A

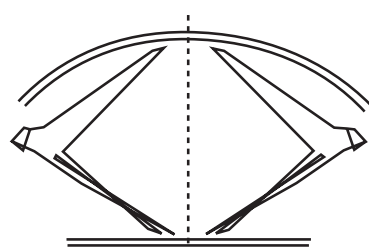

B

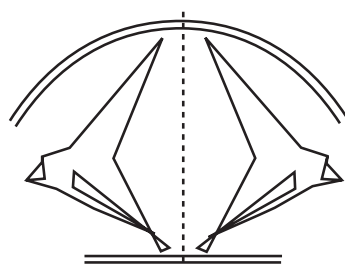

C limb movements can be simultaneous. Carettochelys also has a limb morphology (shoulder and paddles) that is closest to that of marine turtles.

The locomotor adaptations of aquatic and terrestrial turtles differ fundamentally. During terrestrial locomotion, the limbs must provide both support and propulsion, whereas in aquatic locomotion, the water supports the body, and propulsive forces derive entirely from the limbs pushing against the water. On account of the rigid trunk and the weight of the shell, terrestrial walking in such slow animals implies particular conditions. Jayes \& Alexander (1980), and Van Leeuwen et al. (1981) noted that the vertical components of muscular forces used in walking must be very much larger than the horizontal components in order to counterbalance body weight. The girdles play a fundamental role in supporting the trunk in the terrestrial environment because they act like beams to support the shell (Walker, 1962, 1971a, 1973). In contrast, the girdles do not play such a supporting role in the aquatic environment. The streamlined shape of the body is associated with hypertrophied flapping forelimbs, which gives an advantage in terms of locomotor efficiency (Davenport et al. 1984). Walker (1973) suggested a relationship between the shape of the shoulder girdle and the configuration of the shell. In terrestrial turtles, the angle between the scapular prong and the acromial process is greater than $90^{\circ}$ (Walker, 1973), and the shell is high and domed (Romer, 1956; Iverson, 1992). In some aquatic freshwater turtles, Walker (1973) noted that the angle is considerably less than $90^{\circ}$, and the shell is flat. Our analysis shows that the shoulder girdle varies greatly in shape and proportion in the different groups. The relative lengths and orientations of the three elements (scapular prong, coracoid, acromial process) are directly linked to the shape of the shell (Fig. 7). In terrestrial turtles, the vertical position and the great length of the scapular prong are correlated with the domed shell. In both marine and highly aquatic freshwater turtles, the scapular prong is short and more inclined in association with a long coracoid, and the shell is flat. In comparison with marine turtles, highly aquatic freshwater turtles have a flatter and broader shell associated with a more inclined scapular prong (acute angle between scapular prong and acromial process) (Fig. 7). In spite of living in a freshwater environment, highly aquatic freshwater turtles possess convergent morphological traits with marine turtles correlated with good swimming ability. As noted by Walker (1973), aquatic turtles possess a long coracoid, which gives them a mechanical advantage in swimming in terms of lever arms and muscular attachments. Our study also indicates that their shoulder morphology is directly linked to the streamlined shape of the shell.

\section{Acknowledgements}

We thank the curators of the Anatomie Comparee et Paleontologie collections of the Muséum National d'Histoire Naturelle, Paris, for allowing us to study the material. We also thank Richard Gemel (Herpetologische Sammlung) of the Naturhistorisches Museum, Vienna, for the loan of a particularly rare specimen (Carettochelys insculpta). We are especially grateful to Dr F. de Lapparent de Broin for suggestions, and to anonymous reviewers for helpful remarks and stylistic corrections.

\section{References}

Berge C, Penin X (2004) Ontogenetic allometry, heterochrony, and interspecific differences in the skull of African apes, using tridimensional Procrustes analysis. Am J Phys Anthropol 124, 124-138.

Bickham JW, Bull JJ, Legler JM (1983) Karyotypes and evolutionary relationships of Trionychid turtles. Cytologia 48, 177-183.

Bookstein FL, Chernoff B, Elder RL, Humphries JM, Smith GR, Strauss RE (1985) Morphometrics in Evolutionary Biology. In The Geometry of Size and Shape Change, with Examples for Fishes. Spec Publ Acad Nat Sci Philadelphia 15. 
Bookstein FL (1991) Morphometrics Tools for Landmarks Data: Geometry and Biology. Cambridge: Cambridge University Press.

Boulenger GA (1889) Catalogue of the Chelonians, Rhyncocephalians and Crocodiles in the British Museum (Natural History). London (reprinted 1966): British Museum.

Bour R, Dubois A (1984) Nomenclature ordinale et familiale des tortues (Reptilia). Stud Geol Salmenticens Stud Palaeocheloniol 1, 77-86.

de Broin F, (1988) Les tortues et le Gondwana. Examen des rapports entre le fractionnement du Gondwana et la dispersion géographique des tortues pleurodires à partir du Crétacé. Stud Geol Salamanticens Stud Palaeocheloniol 2, 5,103-152.

Cann J (1998) Australian Freshwater Turtles. Singapore: Beaumont Publishing Ltd.

Davenport J, Munks SA, Oxford PJ (1984) A comparison of the swimming of marine and freshwater turtles. Proc $R$ Soc Lond 220, 447-475.

Davenport J, Clough W (1986) Swimming and diving in young loggerhead sea turtles (Caretta caretta L.). Copeia 1986, 53 57.

Davenport J (1987) Locomotion in hatchling leatherback turtles Dermochelys coriacea. J Zool 212, 85-101.

Friant M (1942) Interprétation de la ceinture scapulaire endosquelettique des chéloniens. Bull Mus Hist Nat 5, $303-$ 306.

Gaffney ES (1975) A phylogeny and classification of the higher categories of turtles. Bull Am Mus Nat Hist 155, 387-436.

Gaffney ES (1984) Historical analysis of theories of chelonian relationships. Syst Zool 33, 283-301.

Gaffney ES, Meylan PA (1988) A phylogeny of turtles. In The Phylogeny and Classification of Tetrapods (ed. Benton MJ), pp. 157-219. Oxford: Clarendon Press.

Gaffney ES (1990) The comparative osteology of the Triassic turtle Proganochelys. Bull Am Mus Nat Hist 194, 1-263.

Gaffney ES, Meylan PA, Wyss AR (1991) A computer-assisted analysis of the relationships of the higher categories of turtles. Cladistics 7, 313-335.

Georges A (1988) The Warradjan Carettochelys insculpta Ramsay (Testudinata: Carettochelyidae): a Literature Review and Annotated Bibliography. Canberra: Water Resource Centre.

Goodhall CR (1991) Procrustes methods in the statistical analysis of shape. J R Stat Soc 53, 285-339.

Goodhall CR (1995) Procrustes methods in the statistical analysis of shape revisited. In Current Issues in Statistical Shape Analysis (eds Mardia KV, Gills CA), pp. 18-33. Leeds: Leeds University Press.

Gould SJ (1966) Allometry and size in ontogeny and phylogeny. Biol Rev 41, 587-640.

Gower JC (1975) Generalized Procrustes analysis. Psychometrica 2, 241-248.

Grillner S (1975) Locomotion in vertebrates: central mechanisms and reflex interaction. Physiol Rev 55, 247-304.

Grillner S (1981) Control of locomotion in bipeds, tetrapods and fishes. The nervous system. In Handbook of Physiology (ed. Brooks V), 2, pp. 1179-1236. Bethesda, MD: American Physiological Society.
Hennessy RJ, Stringer CB (2002) Geometric morphometric study of the regional variation of modern human craniofacial form. Am J Phys Anthropol 117, 37-48.

Hildebrand M (1966) Analysis of the symmetrical gaits of Tetrapods. Folia Biotheoretica 6, 9-22.

Hirayama R (1995) Phylogenetic systematics of Chelonioid sea turtles. In Evolution and Migration of Fossil Marine Vertebrates in the Pacific Realm (eds Barnes LG, Inuzuka N, Hasegawa Y), 3, no. 4, pp. 270-284. Academic Press.

Hoffmann CK (1890) Reptilien. I. Schildkröten. In Klassen und Ordnungen Des Thier-Reichs (ed. Bronn HG), 6 (3) 3, pp. 1442. Leipzig: C.F. Winter'sche-Verlagshandlung.

Iverson JB (1992) A Revised Checklist with Distribution Maps of the Turtles of the World. Richmond, Indiana: privately printed.

Jayes AS, Alexander RMcN (1980) The gaits of Chelonians: walking techniques for very low speeds. J Zool Lond 191, 353-378.

Joyce WG, Gauthier JA (2004) Palaeoecology of Triassic stem turtles sheds new light on turtle origins. Proc $R$ Soc Lond $B$ 271, 1-5.

King WF, Burke RL (1997) Crocodilian, Tuatara and Turtle Species of the World: a Taxonomic and Geographic Reference. Washington, DC: Association of Systematics Collections.

Klingenberg CP (1996) Multivariate allometry. In Advances in Morphometrics (eds Marcus LF, Corti M, Loy A, Naylor GJP, Slice, D), pp. 23-49. New York: Plenum Press.

Krzanowski WJ (1988) Principles of Multivariate Analysis. Oxford: Clarendon Press.

Lee MSY (1996) The homologies and early evolution of the shoulder girdle in turtles. Proc $R$ Soc Lond 263, 111117.

Mardia KV, Kent JT, Bibby JM (1979) Multivariate Analysis. Duluth, London: Academic Press.

Meylan PA, Gaffney ES (1989) The skeletal morphology of the Cretaceous cryptodiran turtles, Adocus, and the relationship of the Trionychoidea. Amer Mus Nov 2941, 1-60.

Meylan PA (1996) Morphology and relationships of the early Cretaceous side-necked turtle, Araripemys barretoi (Testudines: Araripemydidae) from the Santana formation of Brazil. J Vertebr Paleontol 16, 20-33.

Mosiman JE, James FC (1979) New statistical methods for allometry with application to Florida red-winged blackbirds. Evolution 33, 444-459.

O'Higgins P, Moore WJ, Johnson DR, McAndrews TJ, Flinn RM (1990) Patterns of cranial sexual dimorphism in certain groups of extant hominoids. J Zool Soc 222, 399-420.

Pace CM, Blob RW, Westneat MW (2001) Comparative kinematics of the forelimb during swimming in red-eared slider (Trachemys scripta) and spiny softshell (Apalone spinifera) turtles. J Exp Biol 204, 3261-3271.

Penin X (1997) Modélisation tridimensionnelle des variations morphologiques du complexe cranio-facial des Hominoidea. Thèse d'Université Paris 6, Paris.

Penin X (1999) Analyse et prévision de croissance crânienne par superposition procruste. Rev Orthop Dento-Faciale 33, 275-286.

Penin X, Baylac M (1999) Comparaison tridimensionnelle des crânes de Pan et Pongo par superpositions procrustéennes. CR Acad Sci Paris 322, 1099-1104. 
Penin X (2000-2003) APS, a Procrustes Software. Freeware: http://www.cpod.com/monoweb/aps.

Penin X, Berge C (2001) Etude des hétérochronies par superposition procruste: application aux crânes de primates Hominoidea. CR Acad Sci Paris 324, 87-93.

Penin X, Berge C, Baylac M (2002) Ontogenetic study of the skull in modern humans and common chimpanzees: neotenic hypothesis reconsidered with a tridimensional Procrustes analysis. Am J Phys Anthropol 118, 50-62.

Ponce de León MS, Zollikofer CPE (2001) Neanderthal cranial ontogeny and its implications for late hominid diversity. Nature 412, 534-538.

Pritchard PCH (1979) Encyclopedia of Turtles. Neptune, NJ: T F H Publications Inc.

Rao CR (1966) Covariance adjustment and related problems in multivariate analysis. In Multivariate Analysis (ed. Krishnaiah PR), Tome 1, pp. 87-103. New York: Academic Press.

Renous S (1988) Retentissement à l'adaptation de la vie pélagique de la tortue luth (Dermochelys coriacea) sur sa locomotion terrestre. Mésogée 48, 79-84.

Renous S, Bels VL (1989) Etude cinématique de la palette natatoire antérieure de la tortue luth Dermochelys coriacea (Vandelli, 1761) au cours de sa locomotion terrestre. Can J Zool 69, 495-503.

Renous S (1993) Comparison between aquatic and terrestrial locomotions of the leatherback sea turtle (Dermochelys coriacea). J Zool Lond 230, 357-378.

Renous S (1995) The ontogeny of locomotion in marine turtles. In Scientia Herpetologica (eds Llorente GA, Montori A, Santos X, Carretero MA), pp. 112-119. Barcelona: Associación Herpetológica española.

Renous S, Bels VL, Davenport J (1999) Locomotion in marine Chelonia: adaptation to the aquatic habitat. Hist Biol 14, 1 13.
Rohlf FJ, Slice DE (1990) Extensions of the Procrustes methods for the optimal superimposition of landmarks. Syst Zool 39, 40-59.

Romer AS (1956) The Osteology of the Reptiles. Chicago: University Chicago Press.

Shaffer HB, Meylan P, McKnight ML (1997) Tests of turtle phylogeny: molecular, morphological, and paleontological approaches. Syst Bio/ 46, 235-268.

Van Leeuwen JL, Jayes AS, Alexander RMcN (1981) Estimates of mechanical stresses in tortoise leg muscles during walking. J Zool Lond 195, 53-69.

Walker WF (1962) Aspects of the functional anatomy of the chelonian pectoral girdle and limb. Am Zoo/ 2, 566 (abstract).

Walker WF (1971a) A structural and functional analysis of walking in the turtle, Chrysemys picta marginata. J Morph 90, 263-279.

Walker WF (1971b) Swimming in sea turtles of the family Cheloniidae. Copeia 2, 229-233.

Walker WF (1972) Body form and gait in terrestrial vertebrates. Ohio J Sci 72, 177-183.

Walker WF (1973) The locomotor apparatus of Testudines. In Biology of the Reptilia (eds Gans C, Parsons TS), Vol. 4, pp. 1-51. New York: Academic Press.

Walker WF (1979) Locomotion. In Turtles; Perspectives and Research (eds Harless M, Morlock H), pp. 435-454. New York: Wiley.

Williams TL (1981) Experimental analysis of the gait and frequency of locomotion in the tortoise, with a simple mathematical description. J Physiol 310, 307-320.

Zug GR (1971) Buoyancy, locomotion, morphology of the pelvic girdle and hindlimb, and systematics of Cryptodiran turtles. Misc Publ Mus Zool Univer Mich 142, 1-90.

Zug GR (1972) A critique of walk pattern analysis of symmetrical quadrupedal gaits. Anim Behav 20, 436-438. 